\title{
Role of Fresh Dead Wood in the Epidemiology and the Biological Control of the Chestnut Blight Fungus
}

Joana Beatrice Meyer, ${ }^{\dagger}$ Swiss Federal Institute for Forest, Snow and Landscape Research (WSL), CH-8903 Birmensdorf, Switzerland; Loïc Chalmandrier, Swiss Federal Institute for Forest, Snow and Landscape Research (WSL), CH-8903 Birmensdorf, Switzerland; Landscape Ecology, Institute of Terrestrial Ecosystems, ETH Zürich, Switzerland; and Department of Botany, University of Wyoming, Laramie, WY 82071-2000, U.S.A.; and Fabio Fässler, Christopher Schefer, Daniel Rigling, and Simone Prospero, Swiss Federal Institute for Forest, Snow and Landscape Research (WSL), CH-8903 Birmensdorf, Switzerland

\begin{abstract}
The invasive fungus Cryphonectria parasitica, the causal agent of chestnut blight, is able to survive and sporulate on the bark of fresh dead Castanea sativa wood for at least 2 years. Here, we experimentally investigated the role of fresh dead wood in the epidemiology of chestnut blight, specifically in the spread of the hyperparasitic virus Cryphonectria hypovirus 1 , which acts as biocontrol agent of $C$. parasitica. A total of 152 artificially initiated, virulent bark cankers in four chestnut stands were treated with virus-infected asexual spores originating either from sporulating dead wood or from a spore suspension. Molecular markers for both the virus and the fungal carrier were used to examine the spread

of the applied biocontrol virus. Fourteen months after treatment, 42 to $76 \%$ of the conidial spray-treated cankers and 50 to $60 \%$ of the cankers exposed to a sporulating dead stem had been virus infected by the applied hypovirulent conidia in all four study sites. Virus infection reduced canker expansion and promoted canker healing (callusing). Thus, fresh chestnut dead wood may play an important role in supporting the successful spread of natural hypovirulence in chestnut forests. Further, combined with the application of virus-infected conidial suspensions, it may help promote the establishment of artificially released hypoviruses in chestnut stands to control chestnut blight.
\end{abstract}

The ascomycete fungus Cryphonectria parasitica (Murr.) Barr, the causal agent of chestnut blight, is a necrotrophic pathogen causing perennial bark lesions (cankers) on the stem and branches of susceptible host trees, particularly species of the genus Castanea (Rigling and Prospero 2018). Parts of the tree distal to the infection point may wilt and die. Originating from eastern Asia, C. parasitica was accidentally introduced into Europe in the 1930s, where it became invasive and affected the European chestnut (Castanea sativa Mill.). Following an initially high tree mortality, beginning in the 1950s many chestnut stands started to recover because of the spontaneous spread of a hyperparasitic mycovirus (Heiniger and Rigling 1994).

Cryphonectria hypovirus 1 (CHV1) is an RNA virus located in the cytoplasm of $C$. parasitica (Shapira et al. 1991). Its presence reduces virulence and sporulation capacity of the infected fungal strain, causing hypovirulence (Rigling and Prospero 2018). Cankers induced by virus-infected $C$. parasitica strains typically stop expanding and do not kill the affected trees. To date, natural hypovirulence successfully controls chestnut blight in many European regions, but there are certain areas (e.g., in parts of Southern and Northern Europe) where this is still not the case.

CHV1 does not occur outside its fungal host and is transmitted either horizontally or vertically (Rigling and Prospero 2018). Horizontal transmission by cytoplasmic exchange can occur after hyphal anastomosis between $C$. parasitica strains belonging to the same vegetative compatibility (vc) type. Vertical transmission enables spread of the virus by asexual spores (conidia). In fact, a variable proportion of conidia produced by virus-infected $C$. parasitica strains is

${ }^{\dagger}$ Corresponding author: Joana Beatrice Meyer; E-mail: joana.meyer@wsl.ch

Funding: The authors thank the Federal Office for the Environment (FOEN) and the Swiss cantons of Valais and Vaud for financial support.

*The $\boldsymbol{e}$-Xtra logo stands for "electronic extra" and indicates that two supplementary figures and four supplementary tables are published online.

Accepted for publication 28 August 2018.

() 2019 The American Phytopathological Society itself virus infected (e.g., Peever et al. 2000). In contrast, sexual ascospores never carry the virus (Carbone et al. 2004).

C. parasitica may sporulate on the surface of the bark cankers on living trees, in particular on actively growing, virus-free cankers (Rigling and Prospero 2018). Sporulation on nonexpanding, virusinfected cankers is rare or absent, questioning their role in the spread of CHV1 (Peever et al. 2000; Prospero et al. 2006). Prospero et al. (2006) showed that both virus-free and virus-infected strains were able to survive for more than 1 year in preexisting cankers on stacked dead wood stems. Moreover, $C$. parasitica stromata abundantly developed on the surface of former cankers and adjacent bark areas. Sporulation was also observed on healthy stems that were cut and stacked, indicating that these were purely saprophytically colonized by $C$. parasitica (Prospero et al. 2006).

The importance of the saprotrophic activity of C. parasitica (Fig. 1) for the epidemiology of hypovirulence is still poorly understood. In this study, we conducted a field experiment to determine if virusinfected spores produced on dead chestnut wood can transmit the virus to bark cankers on living trees. To simulate sporulating chestnut wood, we inoculated freshly cut stems in the laboratory with a virus-infected $C$. parasitica strain and incubated them until complete colonization and stromata production were observed. In addition, we produced aqueous solutions of virus-infected conidia. Both the sporulating chestnut stems and the conidial suspensions were applied to virus-free cankers, and the spread of both the released virus strain and the fungal carrier strain was followed using molecular markers. So far, only either the viral or the fungal haplotype spread has been studied in field experiments and not both together. Specifically, we determined if the virusinfected conidia are able to infect preexisting virulent cankers on living trees, thereby reducing canker growth and activity. Finally, we tested if the spread of the viral strains in vivo can be forecasted by assessing the biocontrol potential of the fungal strain in vitro.

\section{Materials and Methods}

Chestnut stands. The experiment was conducted in four pure chestnut (C. sativa) coppice stands in Switzerland (Table 1). Two sites were located in the Chablais region, specifically in BexMontet (MON) and Bex-Creux Boyon (CRE), whereas the other two were situated in the La Côte region, one in Vinzel (VIN) and one in Villars-sous-Yens (VSY). In Chablais, $C$. parasitica genotype CpMG30 (vc type EU-1) is dominant, and in La Côte it is genotype 
CpMG15 (vc type EU-2) (Prospero and Rigling 2012). In all four stands, hypovirulence was artificially introduced by treating chestnut blight cankers with virus-infected $C$. parasitica strains (Table 1). Natural hypovirulence only occurs in VSY, where the virus CHV1-M4740 has been found since 2005 (Prospero and Rigling 2016).

Inoculation of artificial cankers. In June 2014, 50 cankers were artificially initiated in each of the sites MON, VIN, and VSY and 37 cankers in CRE, where fewer chestnut trees were available, resulting in a total of 187 cankers. To induce these cankers, a small agar plug taken from the margin of a growing virus-free $C$. parasitica culture was placed into a hole made in the bark of a healthy chestnut sprout using a cork borer (diameter $5 \mathrm{~mm}$ ). Before each hole was made, the bark was disinfected by wiping with $70 \%$ ethanol. For inoculation, an isolate of the most common vc type and microsatellite genotype of the region was used (Prospero and Rigling 2012; Chablais, CpMG30 of EU-1; La Côte, CpMG15 of EU-2). After inoculation, the wounds were sealed with tape. About 3 months after canker inoculation, the tape was removed, and the cankers were treated as stated below.

Treatments. At each experimental site, 20 cankers were treated with sporulating dead wood stems previously inoculated with a virus-infected $C$. parasitica strain, 20 cankers were sprayed with a suspension of virus-infected conidia, and 10 cankers were left untreated as a negative control (16, 16, and 5 cankers, respectively, in CRE).

Dead wood $(D W)$ treatment. For dead wood production, healthy C. sativa stems (6 to $8 \mathrm{~cm}$ in diameter) from a coppice stand in southern Switzerland were cut into 30-cm-long segments and autoclaved for $15 \mathrm{~min}$ at $121^{\circ} \mathrm{C}$. Thereafter, segments were sealed at both ends with melted paraffin wax. Small agar disks (5-mm diameter) from a growing virus-infected $C$. parasitica culture were inserted into 15 holes made in the bark of the dead wood stems with a cork borer and sealed
A

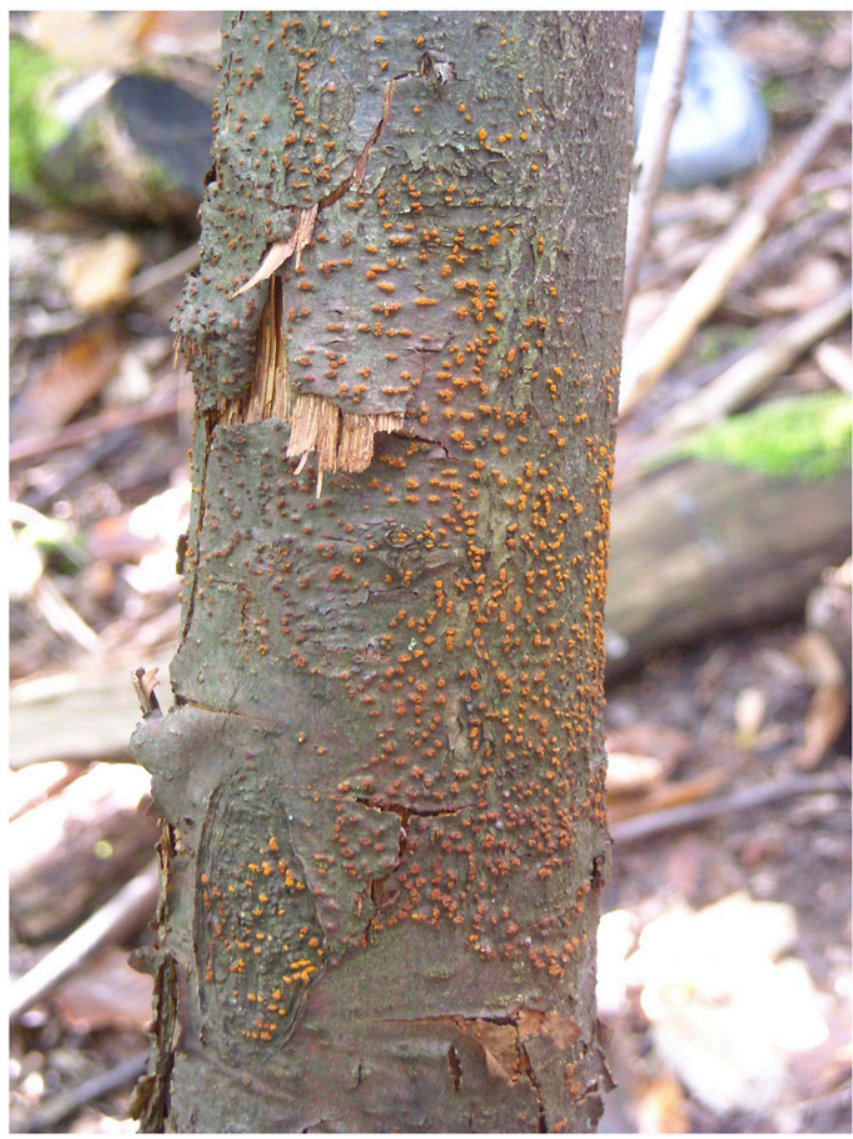

B

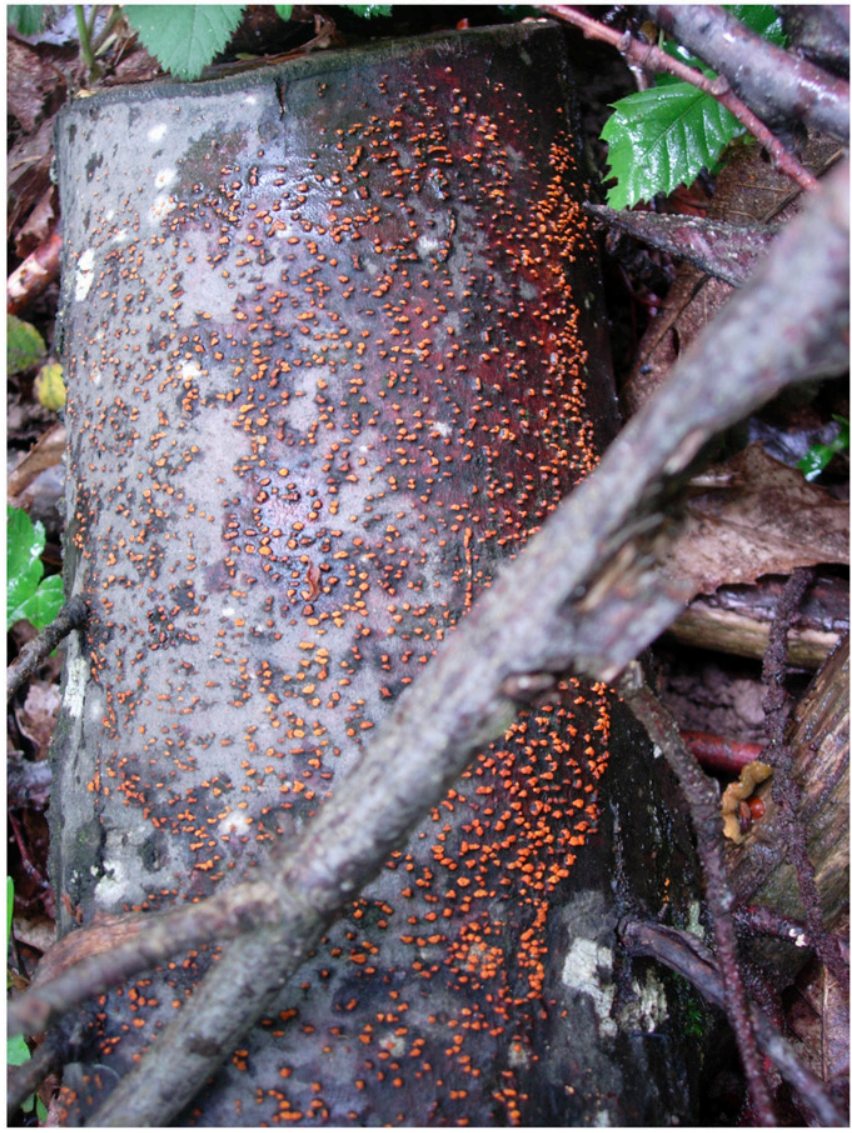

Fig. 1. Stromata of Cryphonectria parasitica produced on dead chestnut wood with intact bark. A, Standing dead chestnut sprout; and B, cut chestnut stem left in the forest. Photos: Phytopathology, Swiss Federal Institute for Forest, Snow and Landscape Research (WSL).

Table 1. Main characteristics of the four experimental sites where this study was conducted

\begin{tabular}{|c|c|c|c|c|}
\hline \multirow[b]{2}{*}{ Characteristics } & \multicolumn{2}{|c|}{ Chablais } & \multicolumn{2}{|c|}{ La Côte } \\
\hline & Bex-Montet (MON) & Bex-Creux Boyon (CRE) & Villars-sous-Yens (VSY) & Vinzel (VIN) \\
\hline Altitude (meters above sea level) & 630 & 480 & 475 & 655 \\
\hline Forest type & Coppice & Coppice & Coppice & Coppice \\
\hline First observation of chestnut blight & 1997 & 1997 & 2005 & 2005 \\
\hline Dominant vc types $^{\mathrm{a}}$ & EU-1, EU-5 & EU-1, EU-5 & EU-2 & EU-2 \\
\hline Dominant fungal genotypes ${ }^{\mathrm{b}}$ & CpMG30 & CpMG30 & CpMG15 & CpMG15 \\
\hline Natural hypovirulence & $\ldots$ & $\ldots$ & CHV1-M4740 & $\ldots$ \\
\hline $\begin{array}{l}\text { First biocontrol treatment }{ }^{\mathrm{c}} \text { (virus } \\
\text { strain released) }\end{array}$ & 2003 (EU-1, CHV1-M3624) & $\begin{array}{l}2004 \text { (EU-1, CHV1-M3624; } \\
\text { EU-5, CHV1-M3625) }\end{array}$ & 2005 (EU-2, CHV1-M4762) & 2007 (EU-2, CHV1-M4762) \\
\hline
\end{tabular}

\footnotetext{
${ }^{\text {a }}$ Prospero and Rigling (2016). vc = vegetative compatibility.

${ }^{\mathrm{b}}$ According to Prospero and Rigling (2012).

${ }^{\text {c }}$ Previous biocontrol treatments were conducted as described by Rigling and Prospero (2018).
} 
with tape. The stems for Chablais were inoculated with the $C$. parasitica haplotype CpMG8 (EU-1; fungal carrier M1709) infected by the virus CHV1-M3623, and those for La Côte with CpMG47 (EU2; fungal carrier M4000) containing the same virus (Table 2). This virus differs in its sequence from the haplotypes used previously for treatments in the stands (Supplementary Table S1). The inoculated dead wood stems were placed onto plastic supports in boxes $(57 \times$ $37 \times 13 \mathrm{~cm}$ ) filled with 4 liters of demineralized water. The boxes were sealed with a transparent plastic sheet and incubated for 6 weeks at temperatures between 15 and $25^{\circ} \mathrm{C}$. After this period, the inoculated C. parasitica haplotype had completely colonized the stems and produced numerous asexual fruiting bodies containing virus-infected spores. In September 2014, the sporulating dead wood stems were attached to trees in the field $50 \mathrm{~cm}$ above the cankers using cable ties.

Conidial spray (SP) treatment. The same $C$. parasitica and virus haplotypes as for the DW treatment were used (i.e., CpMG8 for Chablais and CpMG47 for La Côte). Hypovirulent $C$. parasitica isolates were grown for 2 weeks on potato dextrose agar (PDA; $39 \mathrm{~g} / \mathrm{liter}$; Difco Laboratories, Detroit, MI) in Petri dishes at $25^{\circ} \mathrm{C}$ under light conditions (3,330 lx, 14-h photoperiod, MA Illuminance Meters, Minolta, Japan). For spore harvesting, $15 \mathrm{ml}$ of sterile distilled water was poured on each culture and recollected using a pipette. A $10^{7}$ conidia $/ \mathrm{ml}$ solution was prepared in 1\% methylcellulose (Sigma-Aldrich, St. Louis, MO) (Larena et al. 2010) to protect conidia from desiccation and increase the stickiness of the solution. Before treatment, the virus presence in conidia was verified by cultivating a bulk of them on PDA and assessing the culture type (orange, virus-free; white, virusinfected; Bissegger et al. 1997). In the field, in September 2014 the conidial solution (approximately $2 \times 10^{7}$ conidia per canker) was sprayed on the cankers and distributed evenly with a brush. The treated cankers were sealed with plastic foil to prevent conidia from drying out or being washed away by rain. Because conidia were sprayed directly on the canker surface and only had to penetrate into it for virus transmission, this treatment represented a simplified version of the DW treatment where conidia first had to reach the canker.

Sampling and scoring the cankers and dead wood stems. To isolate $C$. parasitica from the cankers and from the dead wood stems, bark pieces were removed using a bone marrow biopsy needle (diameter $2 \mathrm{~mm}$; Jamshidi gauge, BD, Franklin Lakes, NJ) (Meyer et al. 2015). The biopsy needle was sterilized before each bark piece was removed. The sampling holes in the cankers were sealed with LacBalsam (Frunol Delicia, Delitzsch, Germany) to close a potential entry point for $C$. parasitica spores. $C$. parasitica was isolated from the bark samples as described by Bryner et al. (2014). The presence of the virus in the $C$. parasitica isolates was assessed based on the characteristic white culture morphology induced by a CHV1 infection (Bissegger et al. 1997). If at least one C. parasitica isolate per canker showed white culture morphology, the canker was scored as virus-infected, whereas if all isolates recovered were orange, the canker was considered virus-free.

To determine the effect of a virus infection on canker development and activity, the cankers were measured (length and width) and assessed for activity (active or callused; Bryner et al. 2013) at each sampling date (March 2015, July 2015, and November 2015). During the first two sampling dates (March and July 2015), only half of the cankers and dead wood stems were sampled, but all cankers were measured and scored. At the third sampling event (November 2015), all cankers and dead wood stems were sampled and scored.

Sampling and scoring of natural cankers. In June 2016, a total of 88 natural cankers were sampled (Chablais, 21 cankers in CRE and 22 in MON; La Côte, 24 in VIN and 21 in VSY) to determine possible infection with the released virus haplotype CHV1-M3623. Owing to differences in the distribution of sprout clusters, in Chablais natural cankers were mostly sampled from the same sprout clusters as the experimental cankers, whereas in La Côte samples were taken from different sprouts.

Fungal DNA and viral RNA extraction. RNA was extracted from all virus-infected isolates originating from a canker, but only from one virus-infected isolate per dead wood stem. The extraction was performed with the Plant/Fungi Total RNA Purification Kit (Norgen Biotek, Thorold, ON, Canada), excluding the DNA digestion step to allow further determination of the fungal haplotype by microsatellite genotyping (see below). For cankers and dead wood stems from which only virus-free isolates were recovered, one of the three isolates was randomly selected for DNA extraction and microsatellite analysis. DNA extraction was performed using the KingFisher 96 Flex (Thermo Fisher, Waltham, MA) according to the manufacturer's protocol.

Virus haplotypes. For virus haplotype determination, the complementary DNA synthesis and subsequent amplification/sequencing of a 693-bp region of the open reading frame (ORF) A were performed as described by Prospero and Rigling (2016). ORF A sequences of the virus haplotypes were analyzed with CLC Main Workbench (version 7.6.2) and aligned in MEGA (version 7.0.14). For phylogenetic analysis, the sequences were then separated into two different alignments according to the two regions Chablais (CRE and MON) and La Côte (VIN and VSY). The single alignments were processed with Gblocks (version 0.91b, http://www.phylogeny.fr/, accessed April 11, 2016; Dereeper et al. 2008), trimming all sequences to $568 \mathrm{bp}$. Statistical selection of best-fit models and building of phylogenetic trees were carried out as described by Meyer et al. (2017), but only maximum likelihood analyses were performed. The trees were rooted with the reference sequence (CHV-I Euro7; Chen and Nuss 1999), and nodes were collapsed by support at a 50\% threshold. Based on the phylogenetic tree, the virus sequences were assigned to different groups associated with either the applied virus haplotype or virus haplotypes already present in the region (Table 2).

Fungal haplotype. $C$. parasitica isolates were genotyped at 10 polymorphic microsatellite loci, as described by Prospero and Rigling (2012). Allele patterns were then compared with those of the multilocus genotypes used in the experiment and, if no match was found, with those of genotypes occurring in the specific populations or previously identified in Switzerland (Prospero and Rigling 2012).

Biocontrol potential of the $\boldsymbol{C}$. parasitica strains. The performance of the fungal biocontrol strains (Table 2) was estimated by their conidial production (sporulation) and the vertical virus transmission into conidia. Mycelial plugs were punched out from the edge of actively growing 7-day-old cultures with a sterile borer. The plugs

Table 2. Characteristics of the virus-infected Cryphonectria parasitica strains used in the in vitro fitness test

\begin{tabular}{|c|c|c|c|c|c|c|c|c|}
\hline Region & $\begin{array}{l}\text { Fungal } \\
\text { strain }^{\mathbf{a}}\end{array}$ & $\begin{array}{c}\text { Culture } \\
\text { type }^{b}\end{array}$ & Viral strain ${ }^{\mathrm{c}}$ & $\begin{array}{l}\text { Fungal strain } \\
\text { SSR }^{d}\end{array}$ & $\begin{array}{c}\text { vc } \\
\text { type }\end{array}$ & $\begin{array}{l}\text { Host } \\
\text { tissue }\end{array}$ & $\begin{array}{c}\text { Year/location of isolation in } \\
\text { Switzerland }\end{array}$ & Treatment \\
\hline \multirow[t]{3}{*}{ La Côte } & M4000 & $w$ & CHV1-M4000 & CpMG47 & EU-2 & Canker & 1992/Lattecaldo & Deadwood/spray \\
\hline & M4762 & w & CHV1-M4762 & CpMG15 & EU-2 & Canker & 2005/Villars-sous-Yens & Previous treatment $\mathrm{f}^{\mathrm{f}}$ \\
\hline & M4740 & $\mathrm{w}$ & CHV1-M4740 & CpMG15 & EU-2 & Canker & 2005/Villars-sous-Yens & Natural virus \\
\hline \multirow[t]{2}{*}{ Chablais } & M1709 & $\mathrm{w}$ & CHV1-M1709 & CpMG8 & EU-1 & Canker & 1992/Novaggio & Deadwood/spray \\
\hline & M3624 & $\mathrm{w}$ & CHV1-M3624 & CpMG33 & EU-1 & Canker & 1999/Bex & Previous treatment $\mathrm{t}^{\mathrm{f}}$ \\
\hline
\end{tabular}

\footnotetext{
${ }^{\mathrm{b}} \mathrm{W}=$ white (virus-infected; Bissegger et al. 1997).

${ }^{\mathrm{c}}$ CHV1 = Cryphonectria hypovirus 1-infected isolates.

${ }^{\mathrm{d}}$ SSR $=$ microsatellite genotype (Prospero and Rigling 2012).

e vc type = vegetative compatibility type.

${ }^{\mathrm{f}}$ Previous biocontrol treatments were conducted as described by Rigling and Prospero (2018).
}

${ }^{a}$ Fungal strain number in the culture collection of the Swiss Federal Institute for Forest, Snow and Landscape Research (WSL). 
were placed upside down in the center of PDA dishes, which were wrapped with Parafilm and incubated at $24^{\circ} \mathrm{C}$ under a light intensity of 3,330 lx and a 14-h photoperiod. Five replicated plates were prepared for each fungal strain. After 32 days, conidia were washed from the surface of the cultures using $15 \mathrm{ml}$ of sterile water. Serial dilutions were made and the conidia concentration determined using a hemocytometer as described in Bryner and Rigling (2011). Conidial suspensions $(100 \mu \mathrm{l})$ were then spread on PDA and incubated 2 days at room temperature. For each fungal strain, 28 to 96 germinated conidia were selected under a dissecting microscope and transferred onto new PDA plates using a sterile needle. The presence of the virus was determined by assessing the culture morphology (orange or white).

Data analysis. For each treated canker, the following features were assessed: (i) infection by a CHV1 virus, if at least one of the three isolates (upper, middle, lower part) showed a virus-infected phenotype; (ii) infection by the virus haplotype CHV1-M3623, if at least one of the three isolates (upper, middle, lower part) was infected by this specific haplotype used for the experiment; (iii) canker size calculated as an ellipse from the measured width and length of each canker (canker size was log transformed for analysis, because it was not normally distributed); and (iv) canker morphology (active or healed). For each feature, we ran a generalized and linear mixed model using treatment as a fixed effect and nested random effects to represent the experimental sites nested within regions that corresponded to the two studied $C$. parasitica strains (CpMG8 for Chablais and CpMG47 for La Côte). Virus infection and canker morphology were considered as binomial variables, and the logarithm of canker size was included as a Gaussian variable. We assessed if there was a significant site effect by running the model using site and treatment as fixed factors and region as a random effect.
The dynamics of treatment effects over time were assessed using generalized linear mixed models with the following response variables: infection by any CHV1 virus, infection by CHV1-M3623, and canker size (log transformed). Treatment and sampling date were included as fixed factors. Sampled individual and sampling site were included as nested random factors. In the linear model linking canker size to treatment and date, an interactive effect between the two fixed factors was included. Because of the relatively small sample size, it was not possible to test for interactive effects in the models for infection by any virus and infection by CHV1-M3623.

The in vitro biocontrol potential of each hypovirulent $C$. parasitica isolate was evaluated as follows. We used a linear mixed model for the number of spores (log transformed) as a function of fungal strain and a generalized mixed model for the percentage of virus-infected spores as a function of fungal strain (using a binomial error term). Both models included the region (Chablais or La Côte) where the fungal strain was sampled as a random effect.

All graphics and statistical analysis were produced in $\mathrm{R}$ (version 3.4.3). Linear mixed effect models were run using the package nlme (Pinheiro et al. 2018) and generalized mixed effect models using the package lme4 (Bates et al. 2015).

\section{Results}

Experimental cankers. Canker infection by $C H V 1$. In November $2015,92.5 \%$ of the 187 inoculated cankers yielded at least one $C$. parasitica isolate, and $60.7 \%$ were virus infected. At all four sites, the prevalence of CHV1 was significantly higher in treated cankers (DW, 50 to $84 \%$; SP, 68 to $95 \%$ ) than in control (untreated) cankers (0 to $55 \%$ ) (Fig. 2A, Supplementary Table S2). Sequence analysis revealed that $81 \%$ of the virus-infected cankers were infected by
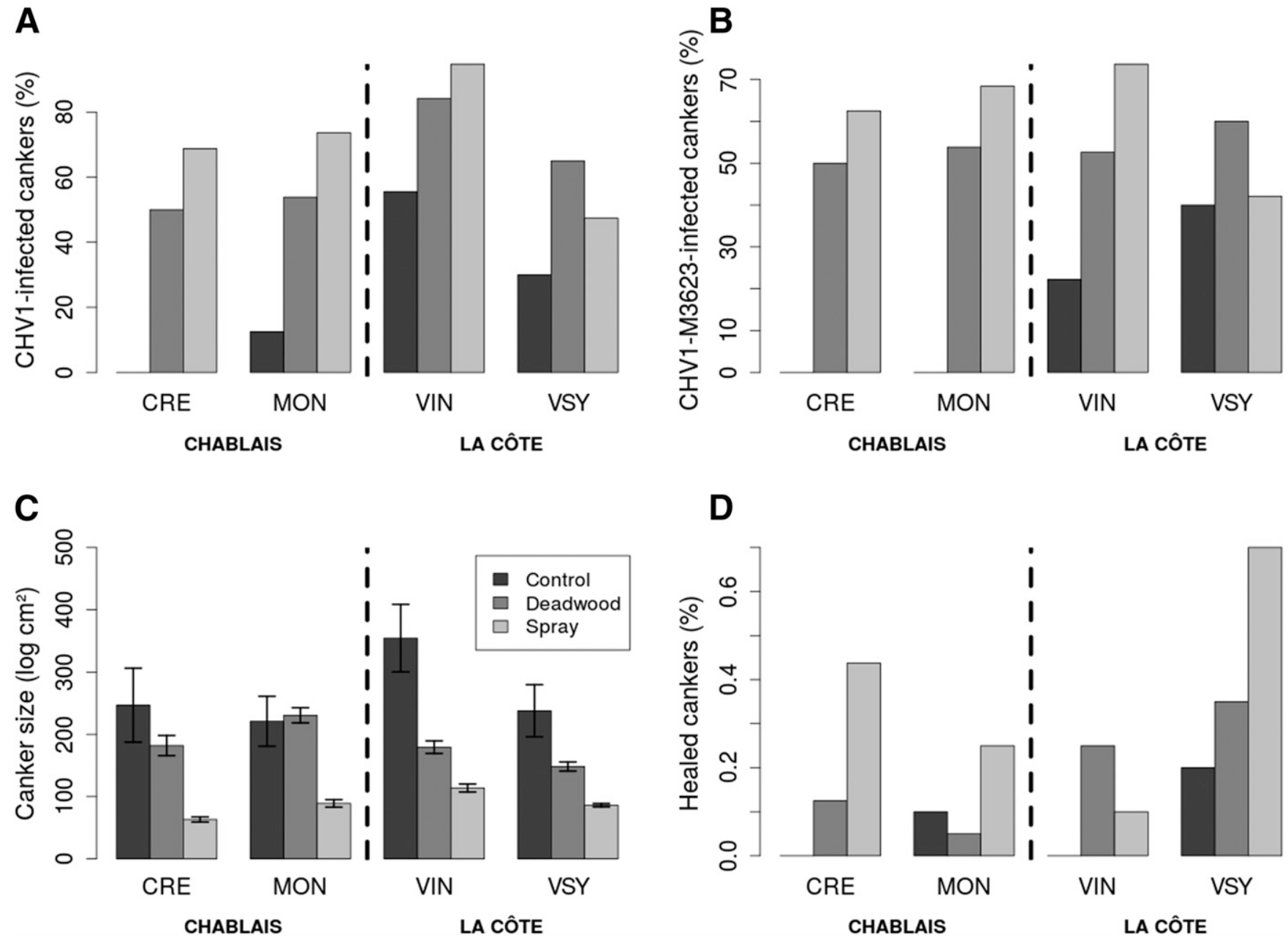

Fig. 2. Presence of the virus in the experimental cankers and effects induced by viral infection. A, Incidence of Cryphonectria hypovirus 1 (CHV1)-infected cankers; B, incidence of cankers infected by the released haplotype CHV1-M3623; C, canker sizes, and D, incidence of healed cankers. 
the applied CHV1-M3623. The cankers treated with DW (42 to 74\% of them were virus-infected across sites) and SP (50 to 60\%) were significantly more likely to be infected with this haplotype than the control cankers (0 to 40\%) (Fig. 2B). No statistical difference was found between the two types of treatment (DW versus SP) in CHV1-M3623 infection probability.

Although different virus-carrying fungal haplotypes were used in the two study regions (CpMG8 for Chablais and CpMG47 for La Côte), the factor region did not significantly affect canker infection by CHV1M3623 (La Côte, 67\% of the cankers; Chablais, 54\%). A site influence was observed for total virus infection but not for CHV1-M3623 infection, with a significantly higher incidence of virus-infected cankers in VIN $(81 \%, P<0.001)$ than in the other sites (CRE, 51\%; MON, $56 \%$; VSY, 52\%) after controlling for the effect of the treatment.

Canker morphology. The presence of CHV1-M3623 significantly reduced canker size, with a significantly stronger effect observed for the SP treatment (Fig. 2C). Nontreated cankers were on average $26.7 \mathrm{~cm}^{2}$ in size, whereas SP-treated cankers were $8.8 \mathrm{~cm}^{2}$ and DW-treated cankers were $18.5 \mathrm{~cm}^{2}$. No differences in the size of CHV1-M3623-infected cankers were found between regions or among sites. Our analysis showed that the DW treatment led, on average, to a $25 \%$ reduction in canker size, and the SP treatment led to a stronger reduction of $62.4 \%$. The incidence of healed cankers in November 2015 differed between the treatments: significantly more SP-treated cankers (10 to 70\%) were healed (Fig. 2D) compared with DW-treated (5 to 35\%) and nontreated cankers (0 to 20\%). Among study sites, the incidence of healed cankers across treatments was significantly higher (46\%) in VSY than in the other three sites (CRE, 24\%; MON, 14\%; VIN, 14\%).

Treatment effect over time. Overall, CHV1 and CHV1-M3623 infection of the cankers increased for all canker groups (SP treated, DW treated, and control) between the first and second sampling date (March and July 2015; Figure 3A to D, Supplementary Table S3). From July to November 2015, however, no significant changes in the incidence of infected cankers were observed anymore. Size increased over time for all cankers (Fig. 3E and F). However, as early as July, the growth of SP-treated cankers was significantly reduced compared with control cankers, whereas DW-treated cankers only showed a significant difference in November.

C. parasitica genotypes. Microsatellite profiles were obtained from 170 out of the 173 C. parasitica isolates genotyped. In Chablais, experimental cankers were initiated with CpMG30 and CpMG8 used as the virus carrier. In November 2015, CpMG30 was still present in 95\% of the 75 experimental cankers (Fig. 4). Only four cankers in CRE harbored other haplotypes. In La Côte, the experimental cankers were initiated with CpMG15 and CpMG47 used as the virus carrier. In November 2015, CpMG15 was present in $89 \%$ of the cankers, and 10 cankers were found with other fungal haplotypes (Fig. 4).

Virus haplotypes. Overall, 85 experimental cankers were infected by virus haplotypes, with sequences identical or similar (one to three single-nucleotide polymorphism [SNP] differences) to the applied CHV1-M3623 (Fig. 4, Supplementary Figs. S1 and S2). Other viruses clustered with CHV1-M3625, except for three virus sequences from MON (in a control canker), newly classified as CHV1-MON. In La Côte, viruses not originating from CHV1M3623 clustered either with CHV1-M4762 or CHV1-M4740. Only one CHV1-M4762 haplotype was isolated in VSY, whereas all others were found in VIN. The CHV1-M4740 group was only present in VSY in two cankers.

Survival of C. parasitica on dead wood stems. In November 2015 (14 months after treatments), in La Côte the virus-carrying CpMG47 could still be isolated from $35 \%$ (VSY) and $65 \%$ (VIN) of the dead wood stems, and in Chablais CpMG8 from 44\% (MON) and 70\% (CRE). All C. parasitica cultures isolated from dead wood stems were virus infected.

Natural cankers. C. parasitica genotypes. Microsatellite profiles were obtained for 82 isolates out of 88 natural cankers. In Chablais, nine $C$. parasitica haplotypes were present (Fig. 4), but only two of them were frequent (i.e., CpMG33 and CpMG44). A similar situation was observed in La Côte, with one single haplotype (CpMG15) predominant. Haplotypes CpMG79, CpMG80, CpMG81, CpMG82, CpMG83, and CpMG84 were found for the first time in Switzerland.

Virus haplotypes. A total of 51 CHV1 sequences (26 in Chablais, 25 in La Côte) were obtained from 27 naturally occurring cankers. The released CHV1-M3623 was detected in 10 natural cankers in Chablais, mainly in sprout clusters with a treated experimental canker (Fig. 4, Table 3) and in one case without a treated canker. Other haplotypes belonged to CHV1-M3624 or CHV1-M3625, or to the new haplotype CHV1-MON. In La Côte, none of the natural cankers sampled was infected by CHV1-M3623 (Table 3). The virus-infected natural cankers contained CHV1-M4762, CHV1-M4740, or the new haplotype CHV1-VSY. The latter differed by nine SNPs from CHV1-M4762 and 12 SNPs from CHV1-M4740.

Sporulation and vertical virus transmission in vitro. Sporulation on PDA at $24^{\circ} \mathrm{C}$ was significantly affected by fungal haplotype (Fig. 5A, Supplementary Table S4) and virus transmission into the conidia by the fungus-virus combination (Fig. 5B). The highest vertical transmission rate (91\% infected conidia) was observed for M4762 (La Côte), whereas the lowest rate (13\%) was observed for M3624 (Chablais). Virus-infected haplotypes applied in La Côte produced, on average, more virus-infected spores than haplotypes used in Chablais (75 versus 24\%), even after controlling for haplotype. Vertical transmission rate positively correlated with the amount of spores produced (Fig. 5C).

\section{Discussion}

Although $C$. parasitica is mainly known for being an aggressive primary pathogen on American (Castanea dentata) and European (C. sativa) chestnut, it also can survive and sporulate on the bark of moribund or recently dead chestnut branches or stems for more than 1 year (Prospero et al. 2006). The relevance of dead chestnut wood in forests affected by chestnut blight is, however, still controversial for the epidemiology of the disease, especially regarding the occurrence of hypovirulence. Previously, Prospero et al. (2006) showed that recently dead chestnut wood supports asexual sporulation of CHV1-infected C. parasitica strains and, therefore, might promote natural $\mathrm{CHV} 1$ dissemination. However, the role of dead chestnut wood in biocontrol of chestnut blight remained unclear. Here, we used molecular markers in a field experiment and demonstrated that virulent $C$. parasitica cankers become virus infected by hypovirulent conidia produced on fresh dead wood. As expected, infection by the virus significantly reduced canker growth and promoted canker healing. Fresh dead chestnut wood can, thus, act as reservoir of virus-infected $C$. parasitica inoculum and be beneficial for the natural biological control of the disease.

Fourteen months after DW and SP treatment, most experimental cankers had been infected by the applied hypovirulent conidia in all four study sites. Most likely conidia germinated, hyphal fusion with the canker isolate occurred, and virus was transmitted into the canker isolate. Because the conidial suspension was sprayed directly on the canker surface, whereas the sporulating stem was set $50 \mathrm{~cm}$ above the canker, one might have expected a higher canker infection rate by SP treatment. The results suggest that the amount of virusinfected conidia coming in contact with a virulent canker might not be decisive for virus transmission to the canker. However, more detailed experimental analyses (e.g., treatment with different concentrations of conidia) should be conducted to confirm this hypothesis. The conidia produced on the dead wood stems were most likely washed down to the target cankers by rain water or transported by insects moving along the tree stems. Unlike the virus, the fungal strain of the conidia rarely became established in the target cankers and only acted as virus carrier, as shown before by Hoegger et al. (2003). Virus infection significantly reduced canker expansion in both treatments. The trend over time reveals a faster effect of the SP treatment in comparison with the DW treatment. A similar trend was observed for the healing process of virus-infected cankers. These differences between the two treatments may be owing to the larger amount of virus inoculum provided by the SP treatment than with the DW treatment.

Our findings may have implications for chestnut forest management, because they suggest a possible beneficial role of fresh dead 
wood for the biocontrol of chestnut blight in forest stands where hypovirulence is already present. Previous recommendations were to remove dead chestnut wood from forests with established natural hypovirulence because dead wood fosters sexual reproduction of virus-free $C$. parasitica strains (Bryner et al. 2014; Heiniger and Rigling 1994). An increased diversity of vc types through sexual reproduction might disrupt natural hypovirulence by reducing virus spread. In chestnut stands with no hypovirulence (e.g., at the disease front), removing dead chestnut wood is meaningful because it reduces the amount of substrate on which virulent fungal strains can sporulate. Because bark is the main substrate for $C$. parasitica growth and sporulation, fresh dead wood with intact bark is particularly critical to be removed. In stands where $C$. parasitica is already controlled by CHV1, this sanitation practice may, however, not be that important. For instance, field investigations in Italy evidenced limited tree mortality in unmanaged plots (Turchetti and Maresi

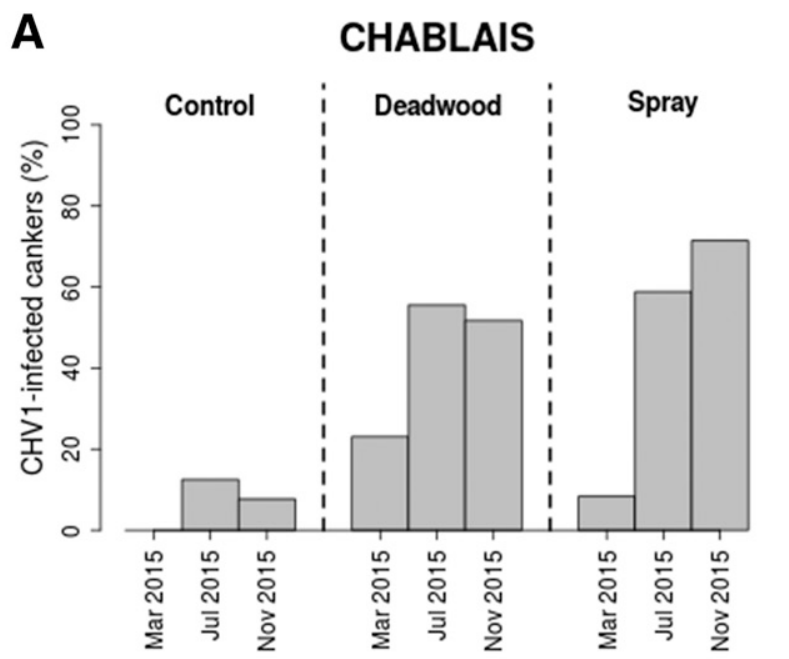

B

\section{LA CÔTE}

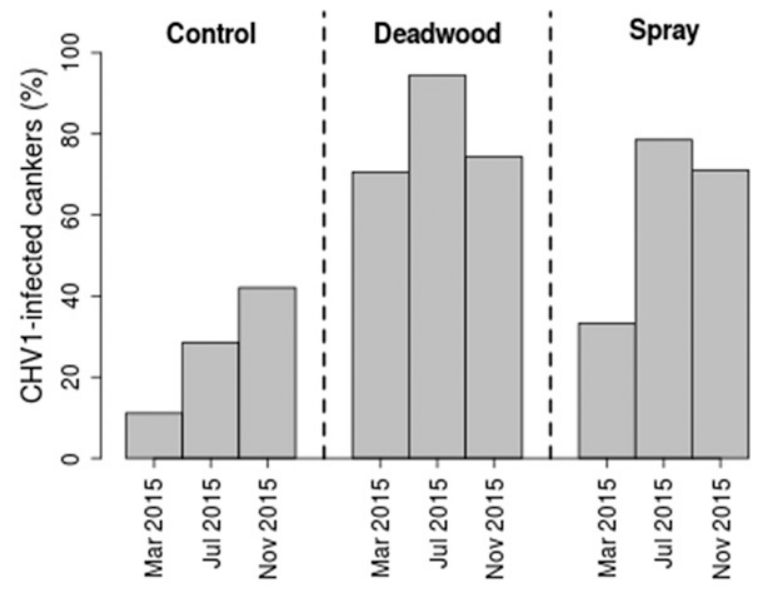

C

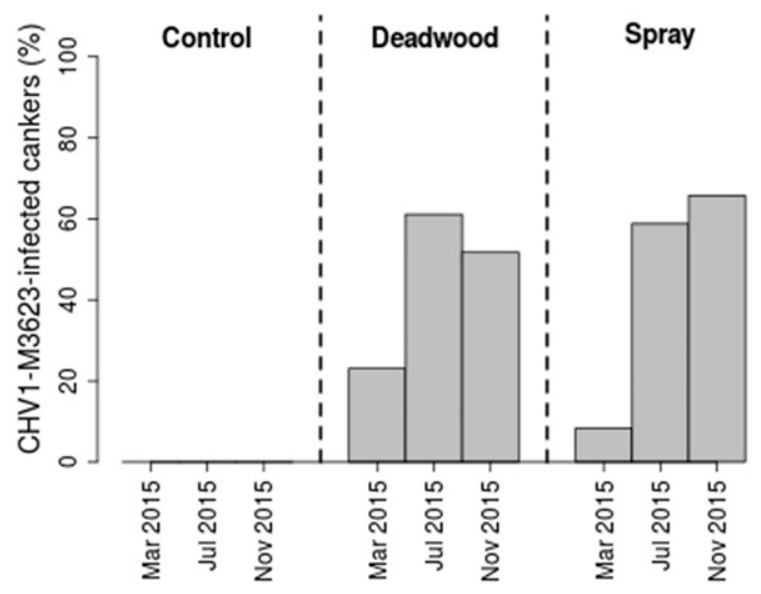

D

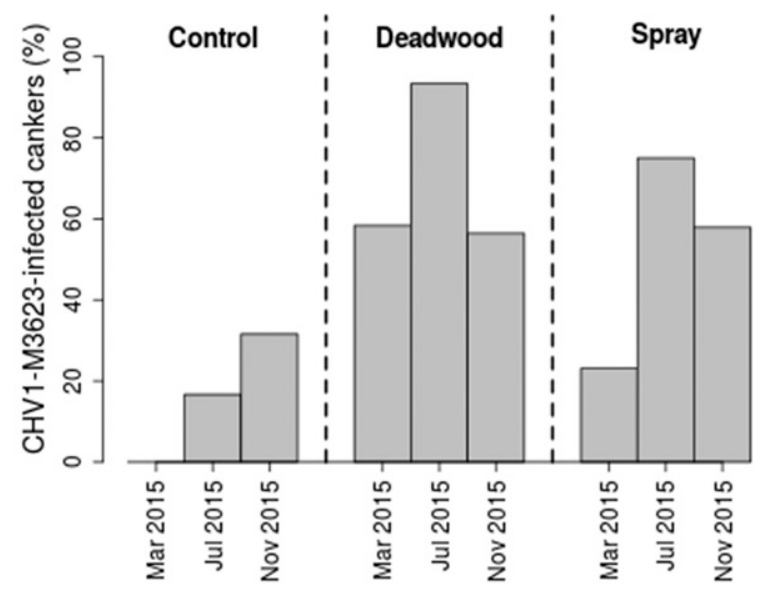

E

$\mathbf{F}$
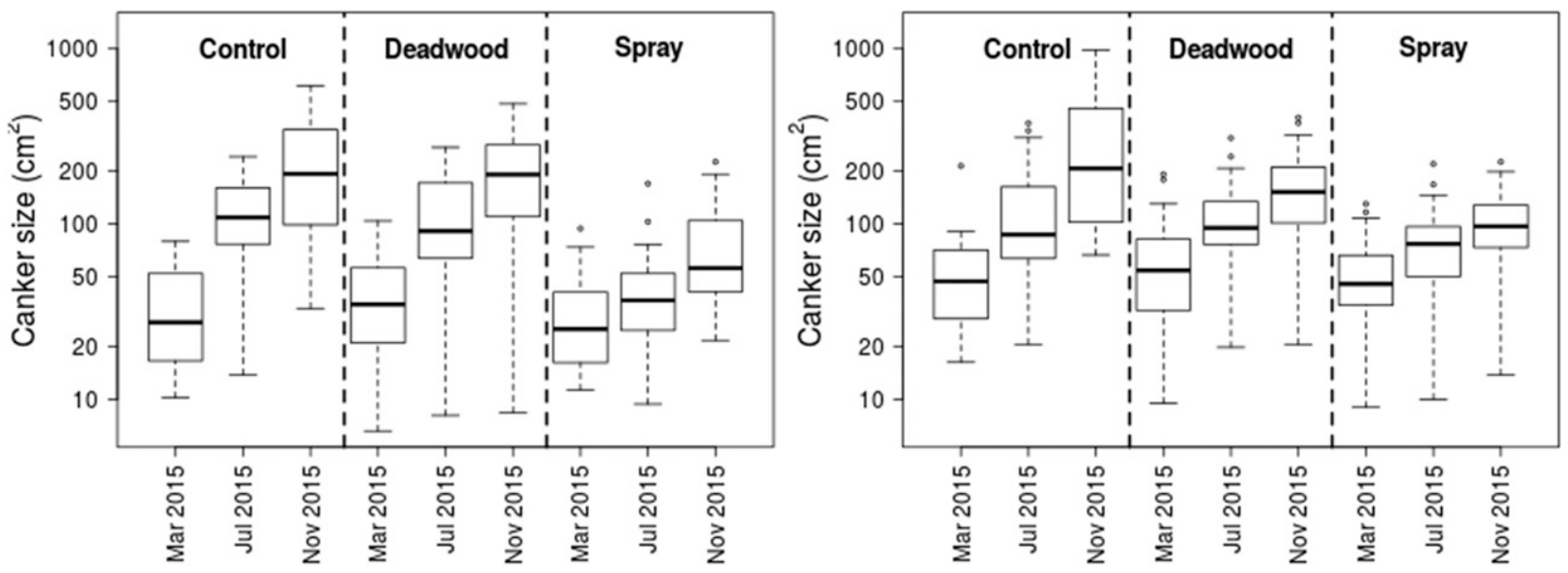

Fig. 3. Development over time (March to November 2015) of the incidence of Cryphonectria hypovirus 1 (CHV1)-infected experimental cankers (A and B), of the incidence of experimental cankers infected by the released haplotype CHV1-M3623 (C and D), and of experimental canker size (E and F) in the two treatments (dead wood and conidial spray), and in the controls (nontreated cankers). 
2008). Our study shows that virus-infected conidia produced on fresh dead wood can transmit the virus to cankers on living trees. Nevertheless, to definitively conclude on the role of fresh dead chestnut wood in the biocontrol of $C$. parasitica, experimental studies comparing the natural spread of CHV1 in managed (i.e., without dead wood) versus unmanaged (i.e., with dead wood) environments would be needed. Particularly helpful for forest managers would be to determine whether there is an incidence threshold for CHV1 in a $C$. parasitica population above which dead wood is beneficial for the spread of hypovirulence and, thus, should be left in the stand.

DW and SP treatments could be used for promoting the establishment of CHV1 in chestnut stands. Currently, canker treatment is performed by applying hypovirulent mycelial slurries to the canker surface or in holes cut in the bark around the margin of a canker (Rigling and Prospero 2018). This method is particularly suitable and effective for young trees with smooth and thin bark (Heiniger and Rigling 2009; Milgroom and Cortesi 2004). However, it has some limitations for the treatment of large and old trees with thick bark, because it is difficult to bore holes and cankers are often diffuse. Moreover, such treatments can be extremely time consuming and expensive, especially if cankers are located in the crown of the trees. Finally, because virus-infected cankers produce a small amount of virus-infected conidia or even do not sporulate at all (Peever et al. 2000; Prospero et al. 2006), the treated cankers rarely contribute to
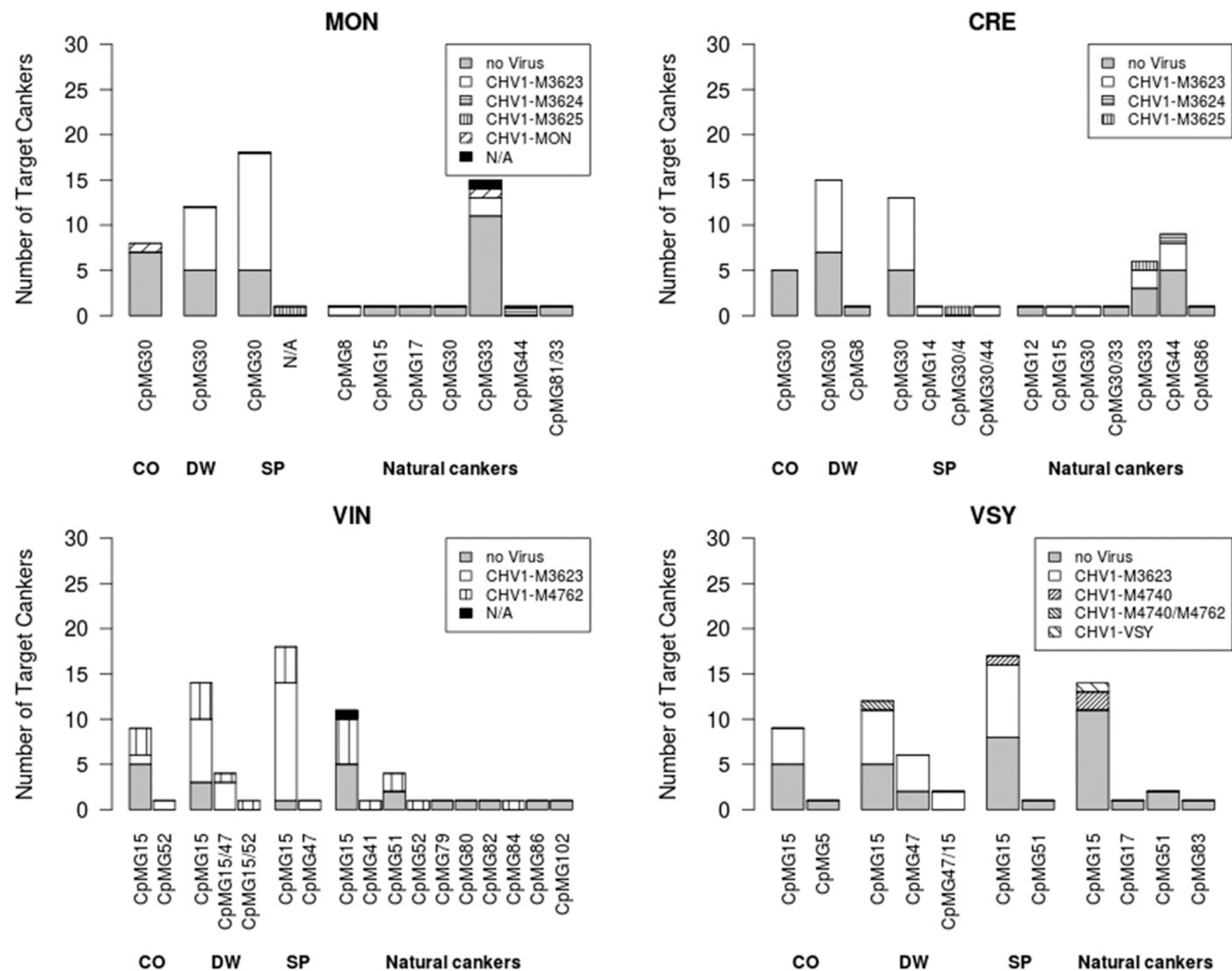

Fig. 4. Cryphonectria parasitica haplotypes and Cryphonectria hypovirus 1 (CHV1) haplotypes identified in the experimental cankers nontreated (CO), treated with dead wood (DW) and treated with conidial spray (SP), and in naturally occurring cankers (natural cankers) at the four study sites.

Table 3. Location and virus infection of the naturally occurring Cryphonectria parasitica bark cankers in the four study sites

\begin{tabular}{|c|c|c|c|c|c|c|c|c|c|}
\hline \multirow[b]{2}{*}{ Stand $^{\mathbf{a}}$} & \multirow[b]{2}{*}{ Region } & \multicolumn{2}{|c|}{ Sprout with a treated canker } & \multicolumn{3}{|c|}{ Sprout cluster with a treated canker } & \multicolumn{3}{|c|}{ Sprout cluster without treated cankers } \\
\hline & & $\begin{array}{c}\text { Cankers } \\
(N)\end{array}$ & $\begin{array}{l}\text { CHV1-M3623 } \\
\text { infected }^{\mathbf{b}}(N)\end{array}$ & $\begin{array}{c}\text { Cankers } \\
(N)\end{array}$ & $\begin{array}{l}\text { Distance range } \\
\text { (average) }\end{array}$ & $\begin{array}{l}\text { CHV1-M3623 } \\
\text { infected }^{\text {b }}(N)\end{array}$ & $\begin{array}{c}\text { Cankers } \\
(N)\end{array}$ & $\begin{array}{l}\text { Distance range } \\
\text { (average) }\end{array}$ & $\begin{array}{c}\text { CHV1-M3623 } \\
\text { infected }(N)\end{array}$ \\
\hline$\overline{\mathrm{CRE}}$ & Chablais & 4 & 1 & 15 & $0.2-1.4(0.6)$ & 5 & 2 & $2.4-3.3(2.8)$ & 1 \\
\hline MON & Chablais & 4 & 2 & 14 & $0.3-2.3(0.8)$ & 1 & 4 & $2.9-8.3(5.5)$ & 0 \\
\hline VIN & La Côte & 2 & 0 & 5 & $0.5-5.0(2.0)$ & 0 & 14 & $1.6-7.3(3.5)$ & 0 \\
\hline VSY & La Côte & 2 & 0 & 7 & $0.3-1.3(0.6)$ & 0 & 11 & $1.4-12(4.5)$ & 0 \\
\hline Total & $\ldots$ & 12 & 3 & 41 & $\ldots$ & 6 & 31 & $\ldots$ & 1 \\
\hline
\end{tabular}

${ }^{\mathrm{a}} \mathrm{CRE}=$ Bex-Creux Boyon; MON = Bex-Montet; VIN = Vinzel; and VSY = Villars-sous-Yens.

${ }^{\mathrm{b}} \mathrm{CHV} 1$ = Cryphonectria hypovirus 1 -infected isolate.

${ }^{\mathrm{c}}$ Distance (in meters) between the sampled natural cankers and the closest experimental canker that was treated with either dead wood or conidial spray. 
virus dispersal. Sporulating dead wood stems could, during the same amount of time, target specific cankers and increase the amount of virus-infected inoculum in the forest.

The SP treatment could be an interesting approach to the therapeutic treatment of cankers, for example, on grafted orchard trees. The effect on canker morphology was considerably greater for SP than DW treatment, because the sprayed cankers were much smaller
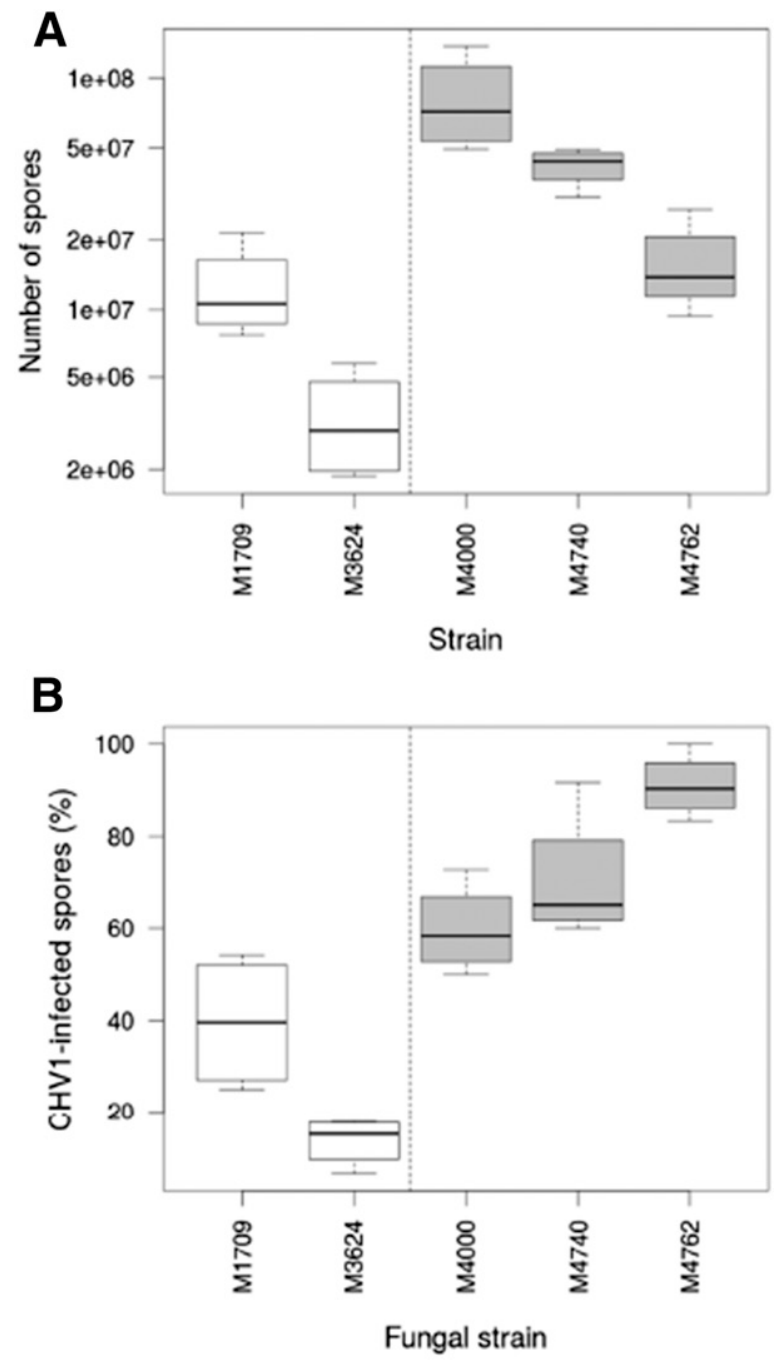

C

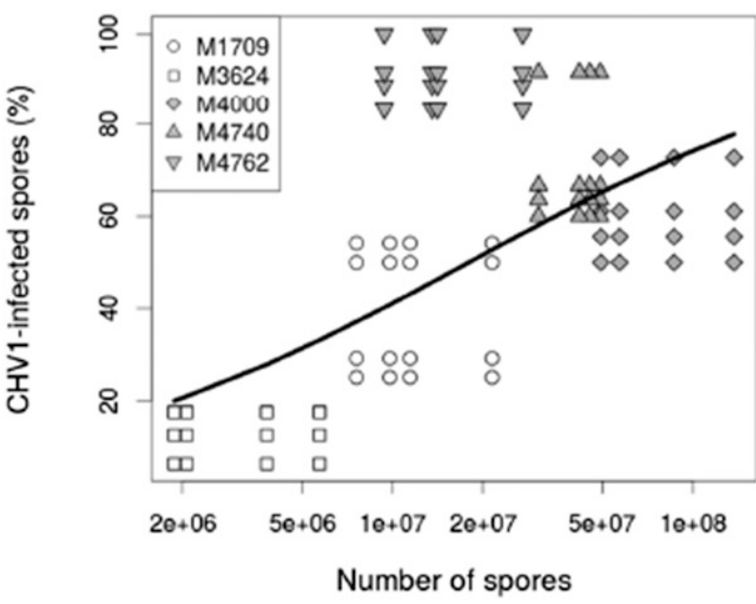

Fig. 5. Biocontrol potential of the virus-infected Cryphonectria parasitica haplotypes from Chablais (white) and from La Côte (gray) (Table 2). A, Number of conidia produced on potato dextrose agar at $24^{\circ} \mathrm{C}$; $\mathbf{B}$, incidence of virus-infected conidia; and $\mathbf{C}$, correlation between the number of produced conidia and their virus infection rate. and healed faster. Covering the cankers with a plastic sheet for 3 months, to prevent the applied spores from drying out and being washed away, might have created favorable conditions (humidity, temperature) for germination of the conidia. SP treatment for the biocontrol of chestnut blight was already tested a few decades ago in North America (Scibilia and Shain 1989). Although the treated cankers were converted, the method was not further developed, mainly because of the high susceptibility of $C$. dentata to $C$. parasitica infection (i.e., new virulent cankers appeared on the same tree and killed it). Because the European chestnut is slightly less susceptible to the pathogen than the American chestnut, this should not be a major problem in Europe. Even if such cankers were to appear, there should be enough time to treat them before they would become lethal. DW and SP treatments could be combined in a forest stand by (i) applying the spray on cankers on living trees, and (ii) either applying the spray on fresh dead wood stems present in the stand or placing sporulating dead wood stems in strategic positions (e.g., the crown of blighted trees). Because the virus disperses mainly by nearest neighbor contact (Liu et al. 2000), its transmission depends on the distance between affected chestnut trees. In our experiment, CHV1-M3623 was able to infect natural cankers that were present either on the same tree or in the same sprout cluster as a treated experimental canker and in one case in a cluster located $2.3 \mathrm{~m}$ away. Therefore, by placing sporulating dead wood stems in the crown of blighted trees, the virusinfected conidia may reach and infect existing cankers. Chestnut stems releasing virus-infected conidia can be produced in the laboratory under controlled conditions, taking advantage of the competitive ability of $C$. parasitica in colonizing the bark of freshly cut chestnut stems.

Before application in the field, several fungal-viral combinations should be tested for their potential effectiveness in the biocontrol of $C$. parasitica. As the present study and previous studies (Melzer et al. 1997) showed, significant differences exist between hypovirulent haplotypes in sporulation ability and vertical transmission rate of the virus. In our case, the viral population was more dynamic in $\mathrm{La}$ Côte than in Chablais (i.e., the viral haplotypes already present in the stands infected the experimental cankers more often). Given that chestnut stands are more widespread in Chablais and hypovirulence was introduced there a few years earlier (2003) than in La Côte (2007) (Heiniger and Rigling 2009), we expected to observe the opposite pattern. Different performances of the hypovirulent $C$. parasitica strains may account for this unexpected result. The biocontrol strains released in Chablais produced significantly fewer virusinfected spores in vitro than the three strains present in La Côte. We found that the incidence of virus-infected spores correlated positively with the number of spores produced. Thus, evaluating spore production might be important for selecting the best biocontrol agent in vitro; this approach should, however, be tested with more hypovirulent fungal strains. Although different vc types are dominant in Chablais and in La Côte, their incidence in the local $C$. parasitica populations is similar (S. Prospero, unpublished data). It is, thus, unlikely that vc type diversity has strongly affected the spread of the released viruses.

\section{Acknowledgments}

We thank Esther Jung and Hélène Blauenstein for support in the laboratory and Melissa Dawes for English revision. We are also grateful to a reviewer for valuable comments on the manuscript.

\section{Literature Cited}

Bates, D., Maechler, M., Bolker, B., and Walker, S. 2015. Fitting linear mixedeffects models using lme4. J. Stat. Softw. 67:1-48.

Bissegger, M., Rigling, D., and Heiniger, U. 1997. Population structure and disease development of Cryphonectria parasitica in European chestnut forests in the presence of natural hypovirulence. Phytopathology 87:50-59.

Bryner, S. F., Prospero, S., and Rigling, D. 2014. Dynamics of Cryphonectria hypovirus infection in chestnut blight cankers. Phytopathology 104:918-925.

Bryner, S. F., and Rigling, D. 2011. Temperature-dependent genotype-bygenotype interaction between a pathogenic fungus and its hyperparasitic virus. Am. Nat. 177:65-74.

Bryner, S. F., Sotirovski, K., Akilli, S., Risteski, M., Perlerou, C., and Rigling, D. 2013. Informative value of canker morphology on the presence or absence of virus infection in chestnut blight cankers. For. Path. 43:496-504. 
Carbone, I., Liu, Y. C., Hillman, B. I., and Milgroom, M. G. 2004. Recombination and migration of Cryphonectria hypovirus 1 as inferred from gene genealogies and the coalescent. Genetics 166:1611-1629.

Chen, B., and Nuss, D. L. 1999. Infectious cDNA clone of hypovirus CHV1Euro7: A comparative virology approach to investigate virus-mediated hypovirulence of the chestnut blight fungus Cryphonectria parasitica. J. Virol. 73:985-992.

Dereeper, A., Guignon, V., Blanc, G., Audic, S., Buffet, S., Chevenet, F., Dufayard, J.-F., Guindon, S., Lefort, V., and Lescot, M. 2008. Phylogeny.fr: Robust phylogenetic analysis for the non-specialist. Nucleic Acids Res. 36: W465-W469.

Heiniger, U., and Rigling, D. 1994. Biological control of chestnut blight in Europe. Annu. Rev. Phytopathol. 32:581-599.

Heiniger, U., and Rigling, D. 2009. Application of the Cryphonectria hypovirus (CHV-1) to control the chestnut blight, experience from Switzerland. Acta Hortic. 815:233-246.

Hoegger, P. J., Heiniger, U., Holdenrieder, O., and Rigling, D. 2003. Differential transfer and dissemination of hypovirus and nuclear and mitochondrial genomes of a hypovirus-infected Cryphonectria parasitica strain after introduction into a natural population. Appl. Environ. Microbiol. 69: 3767-3771.

Larena, I., De Cal, A., and Melgarejo, P. 2010. Enhancing the adhesion of Epicoccum nigrum conidia to peach surfaces and its relationship to the biocontrol of brown rot caused by Monilinia laxa. J. Appl. Microbiol. 109: 583-593.

Liu, Y.-C., Durrett, R., and Milgroom, M. G. 2000. A spatially-structured stochastic model to simulate heterogenous transmission of viruses in fungal populations. Ecol. Modell. 127:291-308.

Melzer, M., Dunn, M., Zhou, T., and Boland, G. 1997. Assessment of hypovirulent isolates of Cryphonectria parasitica for potential in biological control of chestnut blight. Can. J. Plant Pathol. 19:69-77.

Meyer, J. B., Gallien, L., and Prospero, S. 2015. Interaction between two invasive organisms on the European chestnut: Does the chestnut blight fungus benefit from the presence of the gall wasp? FEMS Microbiol. Ecol. 91:fiv122.
Meyer, J. B., Trapiello, E., Senn-Irlet, B., Sieber, T. N., Cornejo, C., Aghayeva, D. González, A. J., and Prospero, S. 2017. Phylogenetic and phenotypic characterisation of Sirococcus castaneae comb. nov. (synonym Diplodina castaneae), a fungal endophyte of European chestnut. Fungal Biol. 121: 625-637.

Milgroom, M. G., and Cortesi, P. 2004. Biological control of chestnut blight with hypovirulence: A critical analysis. Annu. Rev. Phytopathol. 42:311-338.

Peever, T. L., Liu, Y.-C., Cortesi, P., and Milgroom, M. G. 2000. Variation in tolerance and virulence in the chestnut blight fungus-hypovirus interaction. Appl. Environ. Microbiol. 66:4863-4869.

Pinheiro, J., Bates, D., DebRoy, S., Sarkar, D., and R Core Team. 2018. nlme: Linear and Nonlinear Mixed Effects Models. R package version 3.1-131.1. https://CRAN.R-project.org/package=nlme

Prospero, S., Conedera, M., Heiniger, U., and Rigling, D. 2006. Saprophytic activity and sporulation of Cryphonectria parasitica on dead chestnut wood in forests with naturally established hypovirulence. Phytopathology 96: 1337-1344.

Prospero, S., and Rigling, D. 2012. Invasion genetics of the chestnut blight fungus Cryphonectria parasitica in Switzerland. Phytopathology 102:73-82.

Prospero, S., and Rigling, D. 2016. Using molecular markers to assess the establishment and spread of a mycovirus applied as a biological control agent against chestnut blight. BioControl 61:313-323.

Rigling, D., and Prospero, S. 2018. Cryphonectria parasitica, the causal agent of chestnut blight: Invasion history, population biology and disease control. Mol Plant Pathol. 19:7-20.

Scibilia, K., and Shain, L. 1989. Protection of American chestnut with hypovirulen conidia of Cryphonectria (Endothia) parasitica. Plant Dis. 73:840-843.

Shapira, R., Choi, G. H., and Nuss, D. L. 1991. Virus-like genetic organization and expression strategy for a double-stranded RNA genetic element associated with biological control of chestnut blight. EMBO J. 10:731-739.

Turchetti, T., and Maresi, G. 2008. Biological control and management of chestnut diseases. Pages 85-118 in: Integrated Management of Diseases Caused by Fungi, Phytoplasma and Bacteria. A. Ciancio and K. G. Mukerji, eds. Springer, Dordrecht, Netherlands. 